DOI https://doi.org/10.30525/978-9934-26-172-5-5

\title{
МЕТОДИЧЕСКИЕ АСПЕКТЫ ОЦЕНКИ ВЕЛИЧИН ВРЕМЕННЫХ И ЭНЕРГЕТИЧЕСКИХ РЕСУРСОВ МНОГОФУНКЦИОНАЛЬНОЙ РЛС
}

\author{
Наконечный А. А. \\ кандидат технических наук, \\ дочент кафедры вооружения \\ Харьковский национальный университет Воздушных Сил \\ имени Ивана Кожедуба \\ Смирнов О. Л. \\ кандидат технических наук, \\ доиент кафедры вооружения \\ Харьковский национальный университет Воздушных Сил \\ имени Ивана Кожедуба \\ 2. Харьков, Украина
}

\begin{abstract}
Алгоритмы управления работой многофункциональной радиолокационной станции (МФ РЛС), являющейся основным информационным средством любой современной системы противовоздушной/противоракетной обороны (ПВО/ПРО), построены с учётом её тактико-технических характеристик (ТTX). Эти ТTX определяются на этапе разработки РЛС и паспортизуются. Вместе с тем в процессе эксплуатации рассматриваемого образца (типа) радиолокационного вооружения из-за постоянного совершенствования средств воздушного нападения, а также ряда других причин может выявиться несоответствие ТТХ имеющихся МФ РЛС требованиям, предъявляемым к подобным информационным средствам в настоящее время [1, с. 371-374].

Одной их таких ТТХ является пропускная способность РЛС, под которой понимается максимальное количество воздушных целей, обслуживаемых с требуемым качеством на заданном временном интервале [2, с. 134]. Её значение во многом определяется наличием соответствующих временных и энергетических ресурсов МФ РЛС, выделяемых для решения задач обнаружения и сопровождения воздушных целей. Однако в известной литературе отсутствует описание формализованных методов расчёта этих характеристик РЛС, что и обуславливает актуальность настоящей работы.
\end{abstract}


Рассмотрим методологические подходы к оценке величин временных и энергетических ресурсов МФ РЛС.

Оиенка величины временного ресурса МФ РЛС

Под временным ресурсом МФ РЛС понимается длительность такта зондирования - время, расходуемое на выполнение всех операций при реализации режима обнаружения/сопровождения каждой отдельной воздушной цели [3, с. 17].

Технически конкретный режим реализуется в виде так называемого обнаружительного (измерительного) канала МФ РЛС как организованный специальным образом процесс по излучению, приёму и обработке своего набора зондирующих сигналов [4, с. 10-11], поэтому оценка величины временного ресурса МФ РЛС может быть получена с использованием следующего алгоритма:

1. Расчёт периода обращения к обслуживаемой цели как функции её манёвренных характеристик и величины инструментальных ошибок измерения угловых координат МФ РЛС [5, с .208].

2. Определение времени, необходимого для установки луча фазированной антенной решетки (ФАР) РЛС в заданном угловом направлении, а также компенсации помех [3, с. 17].

3. Расчёт частоты повторения одиночного зондирующего импульса с учётом максимальной дальности, на которой возможно обнаружение или происходит сопровождение ранее обнаруженной воздушной цели [6, с. 171].

4. Определение общей продолжительности излучения пачечного сигнала конкретного типа (времени облучения цели) с использованием данных о количестве излучаемых импульсов и частоте их повторения, которая обеспечивает условие однозначности измерения дальности до обслуживаемой цели [6, с. 171].

5. Расчёт искомой величины длительности такта зондирования как суммы времени установки луча ФАР, компенсации помех, времени облучения цели и времени приёма отражённого сигнала. При этом очевидно, что результат должен соответствовать (не превосходить) определённому в п.1 значению периода обращения к обслуживаемой цели, в противном случае необходима корректировка выполненных в п. 2-4 вычислений.

Оиенка величины энергетического ресурса МФ РЛС

Под энергетическим ресурсом МФ РЛС понимается энергия, излучаемая РЛС с некоторой средней мощностью за время облучения обслуживаемой цели [2, с. 322].

Т.к. импульсная мощность излучения РЛС и период повторения зондирующих импульсов связаны очевидной зависимостью со средней 
излучаемой мощностью [2, с. 306], то искомая оценка величины энергетического ресурса МФ РЛС может быть получена как функция количества импульсов в пачке, имеющих заданную мощность и длительность.

Рассчитанные таким образом оценки величин временных и энергетических ресурсов МФ РЛС показывают, сколько этих ресурсов необходимо для обслуживания (обнаружения/сопровождения) конкретной цели. Последующее определение пропускной способности проводится путём сравнения полученных результатов с временными и энергетическими ограничениями, имеющимися у рассматриваемой МФ РЛС как информационного средства системы ПВО/ПРО.

\section{Литература:}

1. Кузьмин С.3. Цифровая радиолокация. Киев, 2000. 428 с.

2. Конторов Д.С., Голубев-Новожилов Ю.С. Введение в радиолокационную системотехнику. Москва, 1971. 368 с.

3. Цифровая обработка сигналов в многофункциональных радиолокаторах. Методы. Алгоритмы. Аппаратура. Под ред. Зайцева Г.В. Москва, 2015. $376 \mathrm{c}$.

4. Бабкин Ю.М., Балагуровский В.А. Синтез многофункционального радиолокатора. Москва, 2006. 108 с.

5. Этингтон Д.А., Карилас П.Дж., Райт Дж.Д. Многофункциональные вращающиеся РЛС с электронным сканированием для обзора воздушного пространства. ТИИЭР. 1985. т. 73, № 2. С. 199-216.

6. Вишнякова Л.В., Кухтенко В.И. Система автоматизированного формирования облика зенитных ракетных комплексов. Техническая кибернетика. 1993. № 6. С. 137-185. 